\title{
Are C-reactive protein levels associated with bacteria in COPD exacerbations?
}

\author{
To the Editor:
}

We have read with interest the article by CLARK et al. [1] about the association of C-reactive protein (CRP) concentrations and microbial aetiology in patients with acute exacerbations of chronic obstructive pulmonary disease (COPD). The study provides interesting new data about the role of viruses in exacerbations and their association with increased levels of CRP. However, the authors found that only $51 \%$ of the exacerbations had an infectious origin and, furthermore, they indicate that the bacterial detection rate was low and was not associated with CRP levels. We believe that some aspects need to be taken into account when interpreting these results.

In the abstract, it is already mentioned that only $13 \%$ of the studied patients had bacteria only in their sputum but the study included 127 patients without sputum samples ( $41.7 \%$ of the total population). As it is impossible to detect any bacteria when no sample is obtained, the prevalence of bacterial detection should always refer to the total number of patients that provided a valid sputum sample. In this case, the prevalence of bacteria detection would be $44 \%$, as presented by the authors in the supplementary material (25\% of bacteria only and $19 \%$ of mixed bacteria/virus detection). These figures are very similar to those obtained in the previous study by PAPI et al. [2] in a population with similar characteristics.

The inclusion criteria of the study were not usual for exacerbations of COPD. There was no spirometric confirmation of COPD and exacerbations were defined as acute cardiorespiratory events. It cannot be ruled out that the low bacterial detection rates were somewhat related to the inclusion of patients with different characteristics from the usual severe COPD population. Purulence or discoloured sputum was not an inclusion criterion and, therefore, it is likely that several nonbacterial exacerbations were included in the analysis. When only patients with discoloured sputum are studied, the rates of bacterial detection range from $59 \%$ to $>80 \%[3-5]$.

CLARK et al. [1] observed that higher CRP concentrations were associated with viral detection rates. However, as a significant number of subjects with viral detection during exacerbation did not provide a valid sputum sample for analysis, it cannot be completely ruled out that some of the episodes classified as "virus only" could actually present mixed viral-bacterial infection. Conversely, they reported that CRP concentrations were not significantly elevated in bacterial exacerbations [1]. However, the median CRP concentration observed in patients in the "bacteria only" group was $20 \mathrm{mg} \cdot \mathrm{L}^{-1}$, higher than that found in the "no pathogen" group $\left(8 \mathrm{mg} \cdot \mathrm{L}^{-1}\right)$. The lack of statistical significance might be due to a Type II error and/or the inclusion of false negatives for bacterial detection in the no-pathogen group because of the lack of sputum samples for analysis. In support of this possibility, almost $40 \%$ of patients with CRP levels $>100 \mathrm{mg} \cdot \mathrm{L}^{-1}$ and almost $30 \%$ of patients with CRP levels between 50 and $100 \mathrm{mg} \cdot \mathrm{L}^{-1}$ belonged to the no-pathogen group. In contrast to their results, GARCHA et al. [6] observed that with the use of more sensitive molecular techniques for sputum microbiological analysis, such as quantitative PCR, CRP levels were significantly higher in bacterial exacerbations. These findings concur with the evidence of the association between the purulence of sputum and the presence of bacteria [3-5] and between the purulence of sputum and CRP levels during an exacerbation of COPD [4]. Furthermore, both elevated CRP levels and sputum purulence are predictors of a poor outcome if antibiotics are not given during an exacerbation $[7,8]$.

We believe that the study by CLARK et al. [1] provides interesting new data about the role of viruses in the exacerbations of COPD; however, the conclusions about the low rate of bacterial aetiology and the lack of association between bacteria detection and CRP are difficult to interpret due to the lack of a significant number of sputum samples in their study population. In any case, the reported results are an important step forward in our understanding of the aetiology of the exacerbations of severe COPD and the interrelation between the different pathogens involved. 
Marc Miravitlles ${ }^{1}$ and Carl Llor ${ }^{2}$

${ }^{1}$ Pneumology Dept, Hospital Universitari Vall d'Hebron, CIBER de Enfermedades Respiratorias (CIBERES), Barcelona, Spain. ${ }^{2}$ Primary Healthcare Centre Jaume I, Tarragona, Spain.

Correspondence: Marc Miravitlles, Pneumology Dept, Hospital Universitari Vall d'Hebron, P. Vall d'Hebron 119-129, 08035 Barcelona, Spain. E-mail: mmiravitlles@vhebron.net

Received: Jan 132015 | Accepted after revision: Jan 192015

Conflict of interest: None declared.

\section{References}

1 Clark TW, Medina MJ, Batham S, et al. C-reactive protein level and microbial aetiology in patients hospitalised with acute exacerbation of COPD. Eur Respir J 2015; 45: 76-86.

2 Papi A, Bellettato CM, Braccioni F, et al. Infections and airway inflammation in chronic obstructive pulmonary disease severe exacerbations. Am J Respir Crit Care Med 2006; 173: 1114-1121.

3 Miravitlles M, Kruesmann F, Haverstock D, et al. Sputum colour and bacteria in chronic bronchitis exacerbations: a pooled analysis. Eur Respir J 2012; 39: 1354-1360.

4 Soler N, Esperatti M, Ewig S, et al. Sputum purulence-guided antibiotic use in hospitalised patients with exacerbations of COPD. Eur Respir J 2012; 40: 1344-1353.

5 Stockley RA, O'Brien C, Pye A, et al. Relationship of sputum color to nature and outpatient management of acute exacerbations of COPD. Chest 2000; 117: 1638-1645.

6 Garcha DS, Thurston SJ, Patel AR, et al. Changes in prevalence and load of airway bacteria using quantitative PCR in stable and exacerbated COPD. Thorax 2012; 67: 1075-1080.

7 Miravitlles M, Moragas A, Hernández S, et al. Is it possible to identify exacerbations of mild to moderate COPD that do not require antibiotic treatment? Chest 2013; 144: 1571-1577.

8 Daniels JMA, Snijders D, de Graaff CS, et al. Antibiotics in addition to systemic corticosteroids for acute exacerbations of chronic obstructive pulmonary disease. Am J Respir Crit Care Med 2010; 181: 150-157.

Eur Respir J 2015; 45: 1514-1515 | DOI: 10.1183/09031936.00005415 | Copyright @eERS 2015

From the author:

We thank M. Miravitlles and C. Llor for their comments. While we do, of course, agree with their statement that it is impossible to detect bacteria when no sample is obtained, this issue is addressed in our study by the subgroup analysis, which examines only those patients with sputum samples tested for bacteria. This group demonstrates identical findings to our main cohort: that C-reactive protein (CRP) levels and body temperature are strongly associated with viral detection (either alone or with bacteria) but not with bacterial detection alone, and suggests that the findings in the main cohort are not due to a lack of sputum samples. We would also like to point out that it is similarly impossible to detect viruses if one does not test for them and of the studies referenced by M. Miravitlles and C. Llor as demonstrating an association between CRP level, sputum purulence and bacterial detection [1-5], none has tested for respiratory viruses apart from that by DANiels et al. [5] and this was not in a standard manner. Interestingly, another study referenced by the authors [6] did systematically test patients with exacerbations for both viruses and bacteria, and demonstrated that although infective exacerbations were associated with sputum purulence compared with those where no pathogen was detected, it found no difference in sputum purulence between exacerbations with viral or bacterial detection. It is also notable that in the randomised, placebo-controlled trial of doxycycline by DANIELs et al. [5], although there was a weak association between CRP levels $>50 \mathrm{mg} \cdot \mathrm{L}^{-1}$ and a favourable response to antibiotics, there was no demonstrable association between antibiotic response and bacterial detection. Viruses were not tested for in a meaningful way in this study but only by serology for selected viruses, and patients with fever were excluded, which would be likely to exclude many patients with viruses. No analysis was conducted to examine the association between the small number of viruses detected by serology and CRP, sputum purulence or response to antibiotics. Therefore, the place of viral detection within this evidence base is uncertain and any conclusion about associations between bacterial detection, sputum purulence, CRP levels and response to antibiotics must acknowledge this uncertainty.

While we understand that our study, like most others, has methodological limitations, it does remain the largest study to examine the role of both viruses and bacteria in hospitalised patients with exacerbation of COPD, and is a real-world clinical study with results generalisable to most patients presenting to emergency departments and admission units. It has demonstrated that the detection of viruses in our cohort was strongly associated with elevated CRP levels (at least up to levels of $100 \mathrm{mg} \cdot \mathrm{L}^{-1}$ ) and temperature but that the detection of bacteria was equally common at all levels of CRP and temperature, at least by conventional culture and pneumococcal antigen testing. This, to us, strongly suggests that the 